Aim of the study: The objective of this research was to become aquainted with patients' knowledge of the calcium role in the primary prevention of colorectal cancer.

Material and methods: A group of 400 patients treated in Nikolay Pirogov Provincial Specialist Hospital in tódź was interviewed by means of the author's own survey in which specific tools were used to become aquainted with patients' knowledge of the calcium role in the primary prevention of colorectal cancer. The necessary statistics were conducted by means of STATISTICA 7.1 and EXCEL 2008 programmes.

Results: The analysis of the results shows that $363(90.7 \%)$ of respondents did not know about the protective role of calcium in the digestive tract and reduce the risk of colorectal cancer. The study shows that 396 (99.0\%) of respondents were not informed by doctors about the protective effect of calcium in the digestive tract. In this survey 357 $(89.25 \%)$ of respondents did not know what is the recommended daily intake of calcium in the diet.

Conclusions: The results of the study shows that patients do not know about the role of calcium in primary prevention of colorectal cancer and were not informed by their doctors about such action of calcium. Patients were not aware of the need to consume the Recommended Dietary Allowance of calcium in the diet, which shows little knowledge of the subjects on the diet. It seems necessary to change the eating habits of patients, while the introduction of nutrition education from an early age in the society. Such actions may prevent in the future many civilization diseases.

Key words: primary prevention, colorectal cancer, knowledge, patients.

\section{The patients knowledge about the role of calcium in the primary prevention of colorectal cancer}

\author{
Konrad Wroński ${ }^{12}$, Roman Bocian ${ }^{1}$
}

1Department of General and Vascular Surgery, Nikolay Pirogov Provincial Specialist Hospital in tódź, Poland

2Postgraduate Studies in Nutrition and Dietetic Counseling at the Department

of Human Nutrition and Consumer, Warsaw University of Life Sciences, Warsaw, Poland

\section{Introduction}

Both morbidity and mortality from colorectal cancer are on a steady increase in Poland. In fact, colorectal cancer is the second most common cancer diagnosed in men and the third most common cancer type in women. Generally, colorectal malignancies are a major health problem in highly developed countries of Europe and Northern America [1-3]. The main risk factors for colorectal cancer include genetic susceptibility, adenomatous polyps, inflammatory bowel diseases and dietary practices [1-5]. Factors known to elevate the risk of colorectal cancer involve diets rich in calories and high in processed foods [3-5]. A well-balanced diet with an appropriate intake of dietary calcium, in turn, has been suggested to be protective against colorectal cancer [4, 5]. Studies conducted in medical research centres across the world indicate that the majority of people consume less calcium than the daily recommended levels. It seems that a diet which satisfies the recommended daily intake (RDI) of calcium may contribute to reducing the number of new cases of colorectal cancer.

The aim of the study was to investigate the extent of patients' knowledge of the role of calcium in the primary prevention of colorectal cancer.

\section{Material and methods}

A survey investigating the patients' knowledge of the role of calcium in the primary prevention of colorectal cancer was conducted in 2009 and 2010 among patients treated in the Nikolay Pirogov Provincial Specialist Hospital in Łódź.

The study involved specially designed patient questionnaires and had the form of a one-off review. The process of sample selection for the study was based on the principle of convenience sampling. The study was carried out in conformity with the structured interview methodology. The questionnaire included a total of nine closed questions. Questionnaire completion by the patients was fully voluntary and anonymous.

The study group comprised 400 patients treated in different units and outpatient clinics of the Nikolay Pirogov Provincial Specialist Hospital in Łódź who consented to the participation in the study and completed the questionnaire correctly.

Calculations necessary for the study were performed using the STATISTICA 7.1 package and EXCEL 2008.

\section{Results}

The study involved a total of 400 patients including 296 (74.0\%) women and 104 (26.0\%) men. The dominant age of respondents (215 out of all surveyed patients, i.e. $53.7 \%$ ) was within range from 45 to 64 years old. As for 
educational background, a total of 291 patients (72.7\%) had completed secondary education. Out of 400 respondents, as many as 384 (96.0\%) lived in a city of more than 500,000 inhabitants (cf. Table 1).

A total of 363 (90.7\%) respondents participating in the study did not know about the protective effect of calcium on the digestive tract and about the benefits of calcium in reducing the risk of colorectal cancer. Out of 400 respondents only 37 (9.3\%) patients knew that calcium plays a protective role.

Furthermore, 396 (99.00\%) respondents claimed they had not been informed by their physicians about the protective effect of calcium on the digestive system. Out of 400 respondents, 4 (1.0\%) patients claimed otherwise.

The questionnaire-based survey also revealed that 357 (89.25\%) respondents did not know the recommended daily dietary intake of calcium. Out of the total number of respondents, 43 (10.75\%) patients heard about the RDI of calcium.

Statistical analysis failed to demonstrate any statistically significant correlations between the respondents' gender, age, educational background or place of residence, and the replies they gave to the questions listed in the questionnaire $(p>0.05)$.

\section{Discussion}

The survey conducted among patients treated in the Nikolay Pirogov Provincial Specialist Hospital in Łódź shows that they do not know about the protective role of calcium in the primary prevention of colorectal cancer. Furthermore, results obtained in the survey demonstrate that the patients were not informed by their physicians about the protective effects of calcium on the digestive system. The surveyed patients did not know about the recommended daily dietary intake of calcium, which reflects their inadequate knowledge of healthy dietary practices.

A search of the MEDLINE database performed by the Authors did not identify any works reporting similar studies aimed at investigating the extent of patients' knowledge of the role of calcium in the primary prevention of colorectal cancer.

\section{Calcium in the body}

Calcium is one of several dozen chemical elements which are present in the human body, and it is classified as a mineral element [6-9]. Similarly to magnesium, potassium, sodium or chloride, calcium is a macronutrient, i.e. a chemical element which is present in the human body in a quantity exceeding $0.01 \%$ of body weight [8-11].

Calcium is absorbed by the body from diet. The absorption of calcium from the digestive tract varies from $10 \%$ to $40 \%$ depending on the type of diet and the chemical form of calcium [7-11]. The efficacy of calcium absorption from the small intestinal mucosa decreases with age [10, 12, 13]. The rate of calcium absorption in elderly men and postmenopausal women is estimated to be on average $0.21 \%$ lower annually [14-20].

One of the aspects analyzed in the study conducted by Szponar et al. [21] in 2000 was individual calcium consumption among the Polish population. The study was carried out between September and November 2000 in a group of
Table 1. The features of the group under examination

\begin{tabular}{|c|c|c|c|}
\hline & & $\begin{array}{c}\text { No. of } \\
\text { patients }\end{array}$ & (\%) \\
\hline \multirow[t]{5}{*}{ Age } & under 25 years old & 7 & 1.7 \\
\hline & from 26 to 44 years old & 167 & 41.8 \\
\hline & from 45 to 64 years old & 215 & 53.7 \\
\hline & over 65 years old & 11 & 2.8 \\
\hline & TOTAL: & 400 & 100.0 \\
\hline \multirow[t]{3}{*}{ Sex } & female & 296 & 74.0 \\
\hline & male & 104 & 26.0 \\
\hline & TOTAL: & 400 & 100.0 \\
\hline \multirow[t]{5}{*}{ Domicile } & in a city above 500.000 citizens & 384 & 96.0 \\
\hline & $\begin{array}{l}\text { in a city from } 25.000 \text { to } 500.000 \\
\text { citizens }\end{array}$ & 15 & 3.8 \\
\hline & in a town below 25.000 citizens & 1 & 0.2 \\
\hline & in the countryside & 0 & 0.0 \\
\hline & TOTAL: & 400 & 100.0 \\
\hline \multirow[t]{5}{*}{ Education } & primary & 0 & 0.0 \\
\hline & vocational & 39 & 9.8 \\
\hline & secondary & 291 & 72.7 \\
\hline & university & 70 & 17.5 \\
\hline & TOTAL: & 400 & 100.0 \\
\hline
\end{tabular}

4,134 subjects aged between 1 and 96 years old. The study group consisted of 1911 men and 2223 women. A total of 2893 subjects were above 18 years of age and 1241 subjects below 18 years old. The study was based on the 24 -hour recall method, the most common technique used in investigating large populations, to gather information about calcium consumption levels. The survey was based on a questionnaire which sought to obtain feedback on foods and beverages consumed by the subjects on the day preceding the study. The questionnaire demonstrated the dietary calcium intake in Poland to be low, averaging $539 \mathrm{mg} /$ day. In the population consisting of girls and women, the average dietary intake of calcium was $539 \mathrm{mg} /$ day, and in the male population it was $666 \mathrm{mg} /$ day.

In 2008 the National Food and Nutrition Institute based in Warsaw developed a set of guidelines regarding the recommended daily dietary intake of calcium for the Polish population [22]. The guidelines have been the accepted standard in Poland since then. Each country establishes the recommended daily dietary intake of calcium for its population on an individual basis. In Poland, the recommended dietary intake of calcium for people in the 19-50 years old bracket is $1000 \mathrm{mg} /$ day, and $1300 \mathrm{mg} /$ day for people above 51 years of age [22]. Comparing the recommended daily dietary intake of calcium with results of the study conducted in 2000, it becomes clear that the calcium intake in Poland is two times lower than the RDI $[21,22]$. The questionnaire designed and distributed as part of the present study reveals that the vast majority of the population does not know the recommended dietary intake of calcium.

\section{Calcium in primary prevention of colorectal cancer}

Colorectal cancer is classified as a diet-related type of cancer. Numerous studies based on cellular and animal models have demonstrated that certain natural components of a daily diet are able to prevent and inhibit the development of colorectal cancer. Such dietary ingredients include calcium, 
dietary fibre, pro- and prebiotics, selenium, vitamin E and folic acid. Evidence from epidemiological studies has confirmed unequivocally that calcium is one of the most important factors decreasing the risk of developing colorectal malignancies.

For examples, a study by San et al. [23] assessed the effects of calcium-rich diets on the risk of colorectal cancer. The study group consisted of 1,760 patients and the control group had 2,481 people aged between 20 and 74 years. Data on calcium content in the diet and lifestyle were collected with the use of specially designed questionnaires evaluating daily calcium intake. The researchers noted a statistically significant correlation between higher dietary intake of calcium and reduced risk of colorectal cancer. San et al. thus recommend a diet rich in dairy products, containing large quantities of calcium and vitamin $D_{3}$.

Palacious et al. [24] sought to establish the relationship between the calcium intake levels and the risk of colorectal cancer. The study was conducted among 433 adult hospital patients in Puerto Rico. The amount of calcium consumed in the diet was investigated using FFQs (Food Frequency Questionnaires) which allow the assessment of calcium content in the foods consumed by study subjects. Colonoscopy was performed in 312 (72\%) patients participating in the study. Based on endoscopic examination, colorectal cancer was found in 117 (37.5\%) patients. In 196 patients (62.5\%) no colorectal cancer was detected. Examination results were then compared with calcium intake levels. Total daily calcium intake (mean consumption: $1180 \mathrm{mg} /$ day) in the group of healthy subjects was higher than in the group of patients with colorectal cancer (mean consumption: 1036 mg/day). The researchers claim that high calcium intake can be responsible for protecting healthy subjects from colorectal cancer.

In another study, Wu et al. [25] examined the correlation between calcium consumption and colorectal cancer on the basis of two prospective studies: NHS (Nurses' Health Study) and HPFS (Health Professionals Follow-up Study). The analysis comprised a total of 87998 women from NHS and 47344 men from HPFS. A statistically significant relationship between calcium intake and the risk of development of colorectal cancer was identified. Higher daily intake of calcium was associated with a lower risk of colorectal cancer both in the studied group of men and women. The study found that the daily calcium intake of 700-800 mg/day was related to a $40-50 \%$ reduction in the incidence of distal colon cancer in these patients compared to subjects whose daily calcium intake was approx. $500 \mathrm{mg}$. The correlation can be related to differences in intestinal $\mathrm{pH}$ level resulting from the presence of calcium which binds to fatty and bile acids in the large intestine. Wu et al. suggest that a 300-400 mg increase in average daily intake of calcium could decrease the incidence of colorectal cancer by ca. $30 \%$. In the USA alone this would reduce colorectal cancer mortality by ca. 16000 cases annually.

A three-year intervention study by Hofstad et al. [26] found that a diet rich in calcium and antioxidants reduced the frequency of recurrence of colorectal polyps among the study patients. The Authors assert that a high-calcium diet contributes to a reduction of the risk of colorectal cancer.
The preventive effect of calcium in colorectal cancer has also been confirmed in studies conducted on mice and rats [27-29]. The protective effect of calcium on the large bowel is believed to involve the inhibition of growth of altered intestinal cells and the suppression of their differentiation in cancer cells. Calcium has also been proven to have antimutagenic properties by binding and deactivating secondary fatty acids [30]. Many researchers are of the opinion that further detailed studies are necessary to investigate cellular mechanisms associated with the protective action of calcium in the large bowel [28, 29].

Despite ample evidence for the role of calcium in primary prevention of colorectal cancer, since there have not been any large multicentre trials, there are as yet no formal guidelines recommending calcium-rich diet to the general population. The Authors of this article maintain that despite there being no such recommendations, Poles should nevertheless be informed about existing recommendations regarding minimum daily dietary intake of calcium and about products containing large amounts of this element.

The best dietary sources of calcium include milk and dairy products which contain the most easily absorbable form of calcium. It is believed that the recommended daily intake of calcium from the diet cannot be satisfied without consuming two glasses of milk or equivalent dairy products on a daily basis [22]. Other products which are relatively high in calcium include canned fish with bones, flour, groats, pulses and leafy vegetables [22]. Medical practitioners should inform their patients that when shopping for food they should read labels and pay close attention to the calcium content of different food products so that they can meet the RDI of calcium adopted by the World Health Organization.

In conclusions, the survey showed that the majority of patients had no knowledge of the role of calcium in the primary prevention of colorectal cancer. Moreover, the respondents did not know the recommended daily dietary intake of calcium. Appropriate daily intake of calcium in physiological conditions not only ensures proper metabolism of bone tissue but also contributes to a reduction of the risk of colorectal cancer. While providing medical care physicians should strive to achieve a change in dietary habits of their patients and inform them of benefits associated with an appropriate dietary calcium intake. It also transpires that state institutions (Ministry of Health, Ministry of National Education, Ministry of Science and Higher Education) ought to undertake actions so that schoolchildren and students have mandatory classes on healthy balanced diet. A change in the society's dietary habits and dietary education from the youngest age, together with dietary education programmes in schools, would certainly result in reduced morbidity and mortality of many lifestyle diseases including malignant cancers.

The authors declare no conflict of interest.

\section{References}

1. Giovannucci E, Willett WC. Dietary factors and risk of colon cancer. Ann Med 1994; 26: 443-52. 
2. Levi F, Pasche C, Lucchini F, La Vecchia C. Dietary fibre and the risk of colorectal cancer. Eur J Cancer 2001; 37: 2091-6.

3. Howe GR, Benito E, Castelleto R, et al. Dietary intake of fiber and decreased risk of cancers of the colon and rectum: evidence from the combined analysis of 13 case-control studies. J Natl Cancer Inst 1992; 84: 1887-96.

4. Bostick RM, Potter JD, Kushi LH, Sellers TA, Steinmetz KA, McKenzie DR, Gapstur SM, Folsom AR. Sugar, meat and fat intake, and nondietary risk factors for colon cancer incidence in lowa women (United States). Cancer Causes Control 1994; 5: 38-52.

5. Parkin DM, Bray F, Ferlay J, Pisani P. Global cancer statistics, 2002. CA Cancer J Clin 2005; 55: 74-108.

6. Moynihan PJ. The relationship between nutrition and systemic and oral well-being in older people. J Am Dent Assoc 2007; 138: 493-7.

7. Guéguen L, Pointillart A. The bioavailability of dietary calcium. J Am Coll Nutr 2000; 19: S119-36.

8. Hildebolt CF. Effect of vitamin D and calcium on periodontitis. J Periodontol 2005; 76: 1576-87.

9. Heitmann BL. Body fat in the adult Danish population aged 35-65 years: an epidemiological study. Int J Obes 1991; 15: 535-45.

10. Moynihan PJ. The role of diet and nutrition in the etiology and prevention of oral diseases. Bull World Health Organ 2005; 83: 694-9.

11. Yoshihara A, Watanabe R, Hanada N, Miyazaki H. A longitudinal study of the relationship between diet intake and dental caries and periodontal disease in elderly Japanese subjects. Gerodontology 2009; 26: 130-6.

12. Shimazaki Y, Shirota T, Uchida K, Yonemoto K, Kiyohara Y, lida M, Saito T, Yamashita Y. Intake of dairy products and periodontal disease: the Hisayama Study. J Periodontol 2008; 79: 131-7.

13. Abrams SA, Wen J, Stuff JE. Calcium and magnesium balance in 9- to 14-year-old children. Am J Clin Nutr 1997; 66: 1172-7.

14. Sheiham A, Steele JG, Marcenes W, Lowe C, Finch S, Bates CJ, Prentice A, Walls AW. The relationship among dental status, nutrient intake, and nutritional status in older people. J Dent Res 2001; 80: 408-13.

15. Amarasena N, Yoshihara A, Hirotomi T, Takano N, Miyazaki H. Association between serum calcium and periodontal disease progression in non-institutionalized elderly. Gerodontology 2008; 25 : 245-50.

16. Reid IR, Mason B, Horne A, Ames R, Reid HE, Bava U, Bolland MJ, Gamble GD. Randomized controlled trial of calcium in healthy older women. Am J Med 2006; 119: 777-85.

17. Szponar L, Sekuła W, Rychlik E, Ołtarzewski M, Figurska K. Badania indywidualnego spożycia żywności i stanu odżywienia w gospodarstwach domowych. Prace IŻŻ 101, Warszawa 2003.

18. Jarosz M, Bułhak-Jachymczyk B. Normy żywienia człowieka. Podstawy prewencji otyłości i chorób niezakaźnych. Wydawnictwo IŻż i PZWL, Warszawa 2008.

19. Sun Z, Wang PP, Roebothan B et al. Calcium and vitamin D and risk of colorectal cancer: results from a large population-based casecontrol study in Newfoundland and Labrador and Ontario. Can Public Health 2011; 102: 382-9.

20. Palacios C, Lopez M, Ortiz AP, Correa MC. Association between calcium intake and colorectal neoplasia in Puerto Rican Hispanics. Arch Latinoam Nutr 2010; 60: 348-54.

21. Wu K, Willett WC, Fuchs CS, Colditz GA, Giovannucci EL. Calcium intake and risk of colon cancer In women and men. J Natl Cancer Inst 2002; 94: 437-46.

22. Hofstad B, Almendingen K, Vatn M, Andersen SN, Owen RW, Larsen $\mathrm{S}$, Osnes $M$. Growth and reccurrence of colorectal polyps: a double-blind 3-year intervention with calcium and antioxidants. Digestion 1998; 59: 148-56.

23. Mølck AM, Poulsen M, Meyer O. The combination of 1alpha,25 $(\mathrm{OH} 2)$-vitamin D3, calcium and acetylsalicylic acid affects azoxymethane-induced aberrant crypt foci and colorectal tumours in rats. Cancer Lett 2002; 186: 19-28.

24. Sitrin MD, Halline AG, Abrahams C, Brasitus TA. Dietary calcium and vitamin D modulate 1,2-dimethylhydrazine-induced colonic carcinogenesis in the rat. Cancer Res 1991; 51: 5608-13.

25. Corpet DE, Pierre F. How good are rodent models of carcinogene sis in predicting efficacy in humans? A systematic review and metaanalysis of colon chemoprevention in rats, mice and men. Eur J Cancer 2005;4: 1911-22.
26. Platz EA, Giovannucci E. Vitamin D and calcium in colorectal and prostate cancers. In: Nutritional Oncology. Heber D, Blackburn GL, Go VLW (eds.). Academic Press, San Diego 1999; 223-52.

\section{Address for correspondence}

\section{Konrad Wrońsk}

Department of General and Vascular Surgery Nikolay Pirogov Provincial Specialist Hospital Wólczańska 195

90-531 Łódź

phone +48426367611

e-mail: konradwronski@wp.pl

Submitted: 10.11 .2011

Accepted: 17.05 .2012 